\title{
Neighbourhood socioeconomic context, individual socioeconomic position, and overweight in young children: a multilevel study in a large German city
}

Steffen Andreas Schüle ${ }^{1 *}$, Rüdiger von Kries ${ }^{2}$, Hermann Fromme ${ }^{3}$ and Gabriele Bolte ${ }^{1}$

\begin{abstract}
Background: The context of the close neighbourhood environment in which children live has gained increasing attention in epidemiological research. This study aimed to investigate if contextual neighbourhood socioeconomic position (SEP) was independently associated with overweight in young children aged 5-7 years while simultaneously considering a wide range of individual socioeconomic determinants and known risk factors for overweight.
\end{abstract}

Methods: Objectively measured body mass index (BMI) data from 3499 children (53\% boys and $47 \%$ girls) from three surveys between 2004 and 2007 clustered in 18 school enrolment zones in the city of Munich, Germany, were analysed with hierarchical logistic regression models. An index of neighbourhood SEP was calculated with principal component analysis using aggregated data. Individual socioeconomic data, maternal BMI, and birth weight were collected with parental questionnaires. We analysed how much of the between neighbourhood variance of overweight was attributable to individual factors and how much was explained by neighbourhood SEP.

Results: The prevalence of overweight, including obesity, was $14.1 \%$. In the final adjusted model low neighbourhood SEP was independently associated with overweight (odds ratio $(O R)=1.42,95 \%$ confidence interval $(\mathrm{Cl})=1.00-2.00$ ) compared to high neighbourhood SEP. On the individual level low parental education $(\mathrm{OR}=1.99,95 \% \mathrm{Cl}=1.49-2.65)$ or middle parental education ( $\mathrm{OR}=1.50,95 \% \mathrm{Cl}=1.16-1.95)$ compared to high parental education and nationality of the child other than German ( $\mathrm{OR}=1.53,95 \% \mathrm{Cl}=1.17-1.99)$ compared to German nationality were independently associated with overweight.

Conclusions: Whereas individual determinants were the main drivers in explaining between neighbourhood variance, neighbourhood SEP additionally explained differences in overweight between neighbourhoods. Thus, considering neighbourhood context in intervention planning could result in more effective strategies compared to measures only focusing on individual determinants of overweight.

Keywords: Multilevel study, Hierarchical regression, Neighbourhood, Contextual factors, Children, Overweight, Socioeconomic position

\footnotetext{
* Correspondence: steffen.schuele@uni-bremen.de

${ }^{1}$ Department of Social Epidemiology, Institute for Public Health and Nursing

Research, University of Bremen, Bremen, Germany

Full list of author information is available at the end of the article
} 


\section{Background}

The increase of overweight and obesity in young children in middle and high income countries in recent decades is described as one of the most challenging public health problems [1,2]. Children being overweight or obese are at greater risk of pulmonary, orthopaedic, neurological, gastroenterological, endocrine, or cardiovascular diseases in their later life [3, 4]. Therefore, a deeper understanding of the causes of overweight in younger ages and the identification of population groups which are mostly affected and need appropriate interventions is of great importance.

Socio-ecological approaches targeting supportive environments are attracting increasing attention for overweight prevention [5]. Therefore, the research question how contextual neighbourhood factors influence overweight in children is of great interest. A contextual effect is present if factors on the neighbourhood level are independently associated with individual health outcomes while possible individual level risk factors are simultaneously considered to avoid an ecological fallacy. To separate out potential contextual effects from individual effects a multilevel modelling approach offers an appropriate analytic strategy [6-8].

Recent reviews provide evidence that a low contextual neighbourhood socioeconomic position (SEP) is a good predictor for negative health outcomes in childhood. There is still a great heterogeneity in neighbourhood studies on how indicators of neighbourhood SEP are operationalized and a comprehensive theory is still missing. Measures of income, education and employment on the level of administrative areas, such as census tracts, are the most often used indicators describing neighbourhood SEP [9-12].

We used the term SEP in this paper as suggested by Krieger et al. $[13,14]$. It is defined as a term which combines economic and social resources with prestige-based characteristics which relatively position individuals, households or neighbourhoods in society.

Most studies analysing associations between neighbourhood SEP and child health were conducted in the USA. Moreover, only a minority of studies have analysed how neighbourhood SEP was associated with measures of overweight in younger children while simultaneously taking into account relevant socioeconomic and parental factors on the individual level in order to disentangle their independent associations. There is evidence that parental education and occupation, household income, and household conditions are the most important socioeconomic indicators during childhood [15]. Parental overweight [16] or high birth weight [17] should be additionally considered as important adjustment variables because these factors can confound associations between neighbourhood SEP, individual SEP and overweight in young children.
Therefore, this study aimed to analyse how the socioeconomic context of neighbourhoods was associated with overweight in young children while simultaneously considering indicators of individual SEP in multilevel analysis as well as birth weight and maternal body mass index (BMI) as adjustment variables. A further objective of this study was to determine how much variance of overweight between neighbourhoods was explained by individual factors and how much was attributable to the neighbourhood socioeconomic context.

\section{Methods}

\section{Study population and study area}

Data collection was performed within the health monitoring units in Bavaria (GME, Gesundheits-MonitoringEinheiten) which are organized by the Bavarian Health and Food Safety Authority. Main goal of the GMEs is to monitor health status of children in Bavaria. Therefore, in three consecutive years surveys with identical procedures concerning data collection were conducted within the framework of the obligatory school entrance health examination in three rural and three urban study regions. All parents gave their written informed consent. The ethics committee of the Bavarian medical council approved the procedures of data collection before the first survey [18]. There were only slight modifications of the questionnaires between the surveys.

This analysis considered 3499 children aged 5-7 years in one of the GME study regions, the city of Munich. Data were pooled from the three surveys conducted between 2004 and 2007 in Munich. The children were clustered in 18 school enrolment zones with a range of 117 - 331 children per school district. These districts were used as a proxy for the children's close neighbourhood environment.

\section{Measures of overweight}

Weight and height were objectively measured by trained staff of the local health authority. Age-specific BMI percentile curves specific for boys and girls, respectively, were used to derive cut-offs for defining children as overweight or obese. We used the International Obesity Task Force (IOTF) cut-off values by Cole et al. [19]. In our analysis the definition of overweight did also include children with obesity.

\section{Individual characteristics from parental questionnaires}

We defined three categories of parental education. The highest level of completed education achieved either by the mother or the father was considered. 'High' included a final degree at university or technical college, A-levels, or advanced technical college entrance qualification. 'Middle' included upper secondary school certificate 
or adequate graduation. 'Low' included a lower secondary school certificate or no graduation.

Household equivalent income was calculated based on the reported monthly household net income as disposable income after taxes and social transfers weighted for age and number of household members according to the Organization for Economic Co-operation and Development-modified scale [20]. A relative poverty threshold was defined as $60 \%$ of the median household equivalent income in Bavaria [21]. Three income groups were created: 'low' ( $<60 \%$ of median), 'middle' ( $60 \%$ of median - median), and 'high' (>median). Due to a high number of missing information on household income in our dataset we created an additional income group 'not indicated' including parents who did not respond on their income in order to avoid selection bias [22].

Parental working status was considered as a binary variable. Unemployment within household was applied if both parents were marginally employed at most. The category employment was applied if one parent was at least part-time employed. A binary variable of single parenthood was created by combining three answers about single parent, family status, and living together with a partner. Only responses showing consistency in all three answers were taken into account [22].

Household crowding was present if there was more than one person per room or less than $20 \mathrm{~m}^{2}$ per person available. Nationality of the child was used as an indicator of migration status. Following the rationale of Schenk et al. [23], categories of German nationality and non-German nationality, including dual citizenship, were defined.

Birth weight and BMI of the mother were obtained from parental questionnaires, too. Three categories of birth weight were generated using international cut-offs from the Pediatric Nutrition Surveillance System (PedNSS) by the Centres for Disease Control and Prevention (CDC) [24]: Low (<2500 gram), normal (2500 gram - 4000 gram), and high ( $>4000$ gram). Maternal BMI data were categorized into normal $\left(<25 \mathrm{~kg} / \mathrm{m}^{2}\right)$, overweight $\left(25 \mathrm{~kg} / \mathrm{m}^{2}\right.$ $\left.<30 \mathrm{~kg} / \mathrm{m}^{2}\right)$, and obese $\left(\geq 30 \mathrm{~kg} / \mathrm{m}^{2}\right)$.

\section{Neighbourhood socioeconomic variables}

We considered five aggregated variables on the level of administrative primary school enrolment zones in which the children live. Averages from the years 2006 and 2007 were calculated. From the city council of Munich we obtained data on foreigners and migration background (percentage of residents with no German citizenship, and percentage of residents with a German citizenship and a migration background), and household data (percentage of single parent households). Data on education were provided by microm $\mathrm{GmbH}$, Neuss, Germany (percentage of households with lower education and with vocational training).

\section{Statistical analysis}

All statistical analyses were performed using SAS statistical software package version 9.3 (SAS Institute, Cary, NC, USA).

We performed bivariate logistic regression between socioeconomic neighbourhood variables, individual variables and overweight. All individual variables which were associated with overweight with a Wald's $P<0.2$ in bivariate logistic regression were included in multivariate analysis. All socioeconomic neighbourhood variables which were associated with overweight with a Wald's $P<0.2$ were taken into account for principal component analysis (PCA). This cut-off is recommended for initial covariable selection [25].

PCA was used as a statistical procedure for data reduction of correlated variables because it creates noncorrelated orthogonal linear combinations explaining the maximum of variance [26]. The first component explains most of the variance and was therefore used as an indicator for the socioeconomic neighbourhood environment. Higher values of the index imply a lower neighbourhood SEP. Spearman rank correlation coefficients between socioeconomic neighbourhood variables used for PCA and the first component were calculated to check how each neighbourhood socioeconomic indicator was represented in the index. Finally, the index was categorized into tertiles (high, middle, and low neighbourhood SEP).

The variance inflation factor (VIF) $\left(V I F_{i}=1 / T_{i}\right)$ was used to assess multicollinearity between the covariables. The VIF is calculated with the tolerance (T) $\left(T_{i}=1-R_{i}^{2}\right)$. $R_{i}^{2}$ is the calculated variance of each covariate associated with all other independent variables. A VIF higher than 10 indicates a serious problem of multicollinearity [27-29].

We applied multilevel logistic regression modelling with school districts as random intercepts to correct for clustering of individuals within the same school district [30]. Our calculated index of neighbourhood SEP was modelled as a 2nd level variable. All individual level variables were considered on the 1st level. Multilevel modelling enables to estimate variance between school districts separately from residual variation between individuals. Thus, this modelling approach makes quantification of overweight variance between neighbourhoods being explained by our calculated neighbourhood SEP index possible. The GLIMMIX procedure in SAS was used for calculating multilevel models.

In a first empty null model only school districts were modelled as random intercepts in order to assess the covariance parameters for the random intercept variance of overweight between school districts. In a second model individual level variables were included to analyse how these variables were associated with overweight, and how much of the variance between school 
zones was explained by these factors. In the full third model the index of neighbourhood SEP was added to assess if there was an independent association between neighbourhood SEP and overweight. For multivariate analysis observations with missing values in any independent variable were not taken into account, except for household income. The category 'not indicated' was generated because of a high number of missing values for this variable. For all other variables considered for multivariate analysis the amount of missing values was acceptable $(\leq 7 \%)$.

Multilevel models were adjusted for the three survey years considering each survey as a dummy variable and maternal BMI and birthweight. For the neighbourhood intercept variance estimates covariance tests were performed and $p$-values and confidence intervals were calculated. Based on the neighbourhood intercept variance estimates we calculated the proportional change in variance $(\mathrm{PCV})$ in percent according to the following equation by Merlo et al. [31, 32]: $P C V=\left(\left(V_{\mathrm{a}}-V_{\mathrm{b}}\right) / V_{\mathrm{a}}\right) \times 100$. $V_{\mathrm{a}}$ is the between neighbourhood variance of the empty model and $V_{\mathrm{b}}$ is the between neighbourhood variance including covariables, in the individual model and the full model respectively. As a sensitivity analysis, we performed multiple imputation for missing values for household income. Multiple imputation of hierarchical data is still a research area with remaining issues and there is still no standard procedure to pool covariance estimates from the random intercepts [33]. Therefore, we performed multiple imputation for fixed effects only in order to check if estimates differed to our models considering missing values as an additional income category. We applied cumulative logistic regression imputation within the PROC MIANALYZE procedure in SAS which is appropriate for ordinal variables [34-36]. In order to consider our clustered data structure, school zones were taken into account as dummy variables within the imputation procedure.

\section{Results}

\section{Characteristics of study population}

There were $53 \%$ boys and $47 \%$ girls in the study population. The overall prevalence of overweight, including obesity, was $14.1 \%$. Sex-specific prevalence was similar in boys $(14.0 \%)$ and girls $(14.2 \%) .8 .5 \%$ of the children had a high birth weight and $24.2 \%$ of mothers were overweight or obese. $17.4 \%$ of the parents had a low education. $13.1 \%$ of the families were affected by relative poverty with a household income below $60 \%$ of the median Bavarian equivalent household income. In $6.9 \%$ of households parents were unemployed, $14.4 \%$ reported to be single parents, and $35.5 \%$ of the families were affected by household crowding (Table 1 ).
Table 1 Characteristics of study population

\begin{tabular}{|c|c|c|}
\hline & $\mathrm{N}$ & Percen \\
\hline \multicolumn{3}{|l|}{ Individual Variables } \\
\hline \multicolumn{3}{|l|}{ Overweight ( $N=3499)$} \\
\hline Yes & 494 & 14.1 \\
\hline No & 3005 & 85.9 \\
\hline \multicolumn{3}{|l|}{$\operatorname{Sex}(N=3499)$} \\
\hline Boys & 1856 & 53.0 \\
\hline Girls & 1643 & 47.0 \\
\hline \multicolumn{3}{|l|}{ Nationality of the child $(\mathrm{N}=3479)$} \\
\hline Other than German & 658 & 18.9 \\
\hline German & 2821 & 81.1 \\
\hline \multicolumn{3}{|l|}{ Birth weight $(N=3499)$} \\
\hline Low (<2.500 gram) & 407 & 11.6 \\
\hline Normal (2.500 gram - 4.000 gram) & 2794 & 79.9 \\
\hline High (>4.000 gram) & 298 & 8.5 \\
\hline \multicolumn{3}{|l|}{ BMI mother $(N=3250)$} \\
\hline Normal $(<25$ kg/m²) & 2464 & 75.8 \\
\hline Overweight $\left(25 \mathrm{~kg} / \mathrm{m}^{2}-<30 \mathrm{~kg} / \mathrm{m}^{2}\right)$ & 591 & 18.2 \\
\hline Obese $(\geq 30$ kg/m²) & 195 & 6.0 \\
\hline \multicolumn{3}{|l|}{ Parental education $(\mathrm{N}=3380)$} \\
\hline High & 1971 & 58.3 \\
\hline Middle & 822 & 24.3 \\
\hline Low & 587 & 17.4 \\
\hline \multicolumn{3}{|l|}{ Parental working status $(\mathrm{N}=3405)$} \\
\hline Unemployment within household & 236 & 6.9 \\
\hline At least one parent employed & 3169 & 93.1 \\
\hline \multicolumn{3}{|l|}{ Single parenthood $(\mathrm{N}=3435)$} \\
\hline Single parent & 493 & 14.4 \\
\hline Other & 2942 & 85.7 \\
\hline \multicolumn{3}{|l|}{ Eqivalent household income $(\mathrm{N}=3499)$} \\
\hline 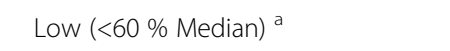 & 457 & 13.1 \\
\hline Middle (60 \% to Median) & 812 & 23.2 \\
\hline High (>Median) & 824 & 23.6 \\
\hline Not indicated & 1406 & 40.2 \\
\hline \multicolumn{3}{|l|}{ Household crowding ( $N=3406)$} \\
\hline Yes & 1210 & 35.5 \\
\hline No & 2196 & 64.5 \\
\hline
\end{tabular}

Contextual Variable

Neighbourhood SEP ( $N=3499)$

$\begin{array}{lll}\text { High } & 974 & 27.8\end{array}$

$\begin{array}{lll}\text { Middle } & 1150 & 32.9\end{array}$

Low

1375

39.3

$N$ total number of observations, SEP Socioeconomic position

${ }^{\mathrm{a}}$ Median equivalent household income in Bavaria 
Principal component analysis and neighbourhood SEP index On the neighbourhood level, except of the percentage of single parent households, all other four aggregated socioeconomic variables were associated with overweight in bivariate logistic regression (Wald's $\mathrm{P}<0.2$ ) and were therefore used for PCA (results not shown). The four neighbourhood variables percentage of foreigners, percentage of German residents with migration background, percentage of households with lower education, and percentage of households with vocational training were significantly correlated with the neighbourhood SEP index derived from the first principal component. Spearman rank correlation coefficients ranged between 0.69 and 0.97 and had $p$-values $<0.05$ (results not shown). According to our calculated neighbourhood SEP index, $39.3 \%$ of the study population lived in school districts with a low neighbourhood SEP (Table 1).

\section{Multilevel logistic regression}

In bivariate logistic regression all variables on the individual level, except sex and single parenthood, were associated with overweight (Wald's $P<0.2$ ). Therefore, sex and single parenthood were not included in multivariate analysis. Low parental education, parental unemployment, low household income, household crowding, and a low neighbourhood SEP were associated with children's overweight. Maternal overweight and a high birth weight were associated with overweight, too (Table 2).

Multicollinearity analysis was performed with the neighbourhood SEP index and all eligible individual variables for multivariate analysis. The values of the VIFs showed acceptable values ranging from 1.0 to 1.8 (results not shown).

In the multilevel null model there was a significant random intercept variance of overweight between neighbourhoods $(p$-value $=0.035)$ (Table 3$)$. In both multilevel models containing individual level variables only (individual model, Table 3) and neighbourhood SEP additionally (full model, Table 3) low or middle parental education and non-German nationality of the child were positively associated with children's overweight. All other characteristics describing individual socioeconomic position remained not significant. In the full model with neighbourhood SEP as a second level variable a low neighbourhood SEP was positively associated with overweight independent from individual factors.

The full model including neighbourhood SEP explained additional $19.1 \%$ between neighbourhood variance of overweight. However, the neighbourhood intercept variance estimates from which the PCV was calculated showed wide confidence intervals.

Our sensitivity analysis with multiple imputed data for missing values on household income revealed similar estimates for individual variables and contextual
Table 2 Bivariate associations of individual factors and neighbourhood SEP, respectively, with overweight

\begin{tabular}{lll}
\hline Variables & OR $(95 \% \mathrm{Cl})$ & $p$-value \\
\hline Sex & & \\
Boy & $0.98(0.81-1.19)$ & 0.8429 \\
Girl & Reference &
\end{tabular}

Nationality of the child

Other than German

$2.05(1.65-2.54) \quad<.0001$

German

Reference

Birth weight

Low $(<2.500$ gram)

$0.92(0.67-1.25) \quad 0.5808$

Normal (2.500 gram - 4.000 gram)

Reference

High (>4.000 gram)

$1.78(1.33-2.40)$

0.0001

BMI mother

Normal $\left(<25 \mathrm{~kg} / \mathrm{m}^{2}\right)$

Reference

Overweight $\left(25 \mathrm{~kg} / \mathrm{m}^{2}-<30 \mathrm{~kg} / \mathrm{m}^{2}\right)$

$2.44(1.93-3.08)$

$<.0001$

Obese $\left(\geq 30 \mathrm{~kg} / \mathrm{m}^{2}\right)$

$3.08(2.19-4.34) \quad<.0001$

Parental Education

$\begin{array}{lll}\text { Low } & 2.53(1.98-3.23) & <.0001 \\ \text { Middle } & 1.76(1.39-2.23) & <.0001 \\ \text { High } & \text { Reference } & \end{array}$

Parental working status

Unemployment within household

$1.63(1.17-2.27)$

0.0042

At least one parent employed

Reference

Equivalent household income

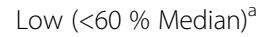

$2.35(1.69-3.27) \quad<.0001$

Middle (60\% to Median)

$1.79(1.32-2.43) \quad 0.0002$

High (>Median)

Reference

Not indicated

$1.68(1.27-2.22)$

0.0003

Single parenthood

Single parent

$1.02(0.77-1.34)$

0.9079

Other

Reference

Household crowding

Yes

$1.55(1.27-1.88) \quad<.0001$

No

Reference

Neighbourhood SEP

High Reference

$\begin{array}{lll}\text { Middle } \quad 1.35(1.03-1.77) & 0.0319\end{array}$

Low $\quad 2.00(1.55-2.56) \quad<.0001$

OR Odds ratio, CI Confidence interval, SEP Socioeconomic position

${ }^{a}$ Median equivalent household income in Bavaria

neighbourhood SEP. Therefore, we reported our multilevel results without multiple imputation of the ordinal income variable because we would like to guarantee valid covariance parameter estimates of our variance components (see methods for further details). Moreover, we analysed potential interactions between our 
Table 3 Multivariate associations between individual SEP, neighbourhood SEP and overweight applying multilevel logistic regression $(N=3125)$

\begin{tabular}{|c|c|c|c|}
\hline Covariables & Null model & Individual model ${ }^{a}$ OR (95 \% Cl) & Full model ${ }^{\mathrm{a}}$ OR $(95 \% \mathrm{Cl})$ \\
\hline \multicolumn{4}{|l|}{ Nationality of the child } \\
\hline Other than German & & $1.53(1.18-1.99)$ & $1.53(1.17-1.99)$ \\
\hline German & & Reference & Reference \\
\hline \multicolumn{4}{|l|}{ Parental Education } \\
\hline Low & & $2.04(1.54-2.72)$ & $1.99(1.49-2.65)$ \\
\hline Middle & & $1.53(1.18-1.99)$ & $1.50(1.16-1.95)$ \\
\hline High & & Reference & Reference \\
\hline \multicolumn{4}{|l|}{ Parental working status } \\
\hline Unemployment within household & & $1.20(0.82-1.77)$ & $1.19(0.80-1.75)$ \\
\hline At least one parent employed & & Reference & Reference \\
\hline \multicolumn{4}{|l|}{ Equivalent household income } \\
\hline Low $(<60 \% \text { Median })^{b}$ & & $1.22(0.82-1.83)$ & $1.18(0.79-1.77)$ \\
\hline Middle (60 \% to Median) & & $1.29(0.93-1.80)$ & $1.26(0.90-1.75)$ \\
\hline High (>Median) & & Reference & Reference \\
\hline Not indicated & & $1.14(0.83-1.58)$ & $1.12(0.81-1.55)$ \\
\hline \multicolumn{4}{|l|}{ Household crowding } \\
\hline Yes & & $0.94(0.74-1.20)$ & $0.93(0.72-1.19)$ \\
\hline No & & Reference & Reference \\
\hline \multicolumn{4}{|l|}{ Neighbourhood SEP } \\
\hline High & & & Reference \\
\hline Middle & & & $1.01(0.71-1.46)$ \\
\hline Low & & & $1.42(1.00-2.00)$ \\
\hline \multicolumn{4}{|l|}{ Measures of variation } \\
\hline Neighbourhood intercept variance $(95 \% \mathrm{Cl})^{c}$ & $0.11(0.046-0.48)$ & $0.047(0.015-0.80)$ & $0.026(0.005-20.37)$ \\
\hline Proportional change in variance & & $-57.3 \%$ & $-19.1 \%$ \\
\hline
\end{tabular}

OR Odds ratio, $\mathrm{Cl}$ Confidence intervall, SEP Socioeconomic position

${ }^{a}$ Adjusted for survey year, birth weight, and BMI of mother, ${ }^{\mathrm{b}}$ Median equivalent household income in Bavaria, ${ }^{\mathrm{C}}$ Covariance parameter estimates from random intercepts on the log odds scale

significant fixed estimates of our final model and no significant interactions were detected (results not shown).

\section{Discussion}

In our final multilevel model low neighbourhood SEP was independently associated with overweight in young children. However, determinants on the individual level explained most between neighbourhood variance of overweight.

Apart from individual SEP we additionally considered birth weight and maternal BMI which are important risk factors for overweight in young children, too $[16,17]$. The association between low neighbourhood SEP and overweight remained significant which strengthened the evidence of an independent impact of neighbourhood SEP on overweight in young children. To the best of our knowledge this is one of the first studies addressing this research question and additionally considering these two important risk factors in multivariate analysis.

In comparison to our findings previous multilevel studies which analysed the influence of neighbourhood SEP on overweight in younger children found an independent association between neighbourhood socioeconomic factors and overweight, too. A longitudinal study in Canadian children aged 2-11 years found out that a poor neighbourhood context based on household income was associated with increasing BMI independent from individual age, sex, education, income, and family structure [37]. Cross-sectional data from the same study which analysed children and youth from 5 to 17 years detected also higher odds for being overweight in neighbourhoods with a low SEP index calculated with data on unemployment, family income, and education [38]. 
One study from the USA, which analysed children aged 6-18 years, found a positive association between decreasing neighbourhood median household income and obesity and a negative association between increasing home ownership on the neighbourhood level and obesity independent from individual age, sex and SEP. As a proxy for individual SEP the insurance status was considered [39].

A study from Germany which analysed data from the school entrance examination found a positive association between a high percentage of low educational households in the neighbourhood and overweight in 6-year old children [40]. In comparison to our study, on the individual level only the mother tongue was considered as an indicator for individual SEP.

All multilevel studies we identified did not consider birth weight and parental overweight as potential adjustment variables. Moreover, there were great differences concerning the included socioeconomic factors on the individual level and the age groups being considered. Besides that, most studies considered single socioeconomic neighbourhood factors, such as measures of income, unemployment, or education, and did not combine them into an index.

Multilevel studies investigating the independent influence of neighbourhood SEP on overweight in adolescents found similar results [41-43]. A detailed discussion of these studies would go beyond the scope of this study because our study focused on younger children. Most of these studies we identified were cross-sectional and strengthened the need for longitudinal studies investigating contextual effects of neighbourhood characteristics along the life course from early childhood up to adolescence in order to disentangle individual, family, and neighbourhood relationships.

Our final multilevel model showed that $19.1 \%$ of overweight prevalence between neighbourhoods was explained by neighbourhood SEP and most of the variance was attributed to individual factors (57.3 \%). However, these estimates should be interpreted with caution because our neighbourhood intercept variance estimates of our individual and full multilevel model showed wide confidence intervals. In only two of our identified studies variance measures were reported. In the study by Grow et al. socioeconomic neighbourhood context explained around $24 \%$ of overweight variance between neighbourhoods [39], whereas in the study by Lange et al. $40 \%$ of BMI variation between neighbourhoods was explained by neighbourhood unemployment [41]. A systematic review by Sellström \& Bremberg [12] identified multilevel studies which studied the impact of neighbourhood factors on child and adolescent health. The review calculated that across studies on average $10 \%$ between neighbourhood variance of the health outcome was explained by contextual factors. Health outcomes in this review were mainly problem behaviours, child maltreatment, injuries, and birth weight. The number and heterogeneity of considered factors on the individual level and the diversity of socioeconomic neighbourhood indicators on the contextual level could explain the large differences of the calculated variance measures.

There are various conceptual models framing the multidimensional pathways how neighbourhood context influence individual health [44-50]. One hypothesis of all these models is that physical environmental factors mediate the effects of neighbourhood SEP on individual health. In the context of overweight, access and quality of food environments, public resources such as parks or playgrounds, and walkability of the built environment could be such potential mediating neighbourhood factors. One hypothesis derived from the environmental justice framework states that built environmental exposures are social unequally distributed both on the individual and the neighbourhood level (exposure variation by SEP) [51]. There is much evidence that a low SEP is inversely associated with a higher environmental burden $[52,53]$. Thus, more studies are needed which investigate underlying mechanisms on the pathway between neighbourhood socioeconomic deprivation and overweight in early childhood.

There are some limitations within our study. One is that our study is cross-sectional. However, for the socioeconomic factors analysed in our study reverse causation is very unlikely. Furthermore, we used administrative school enrolment zones as a proxy for the neighbourhood environment. We were not able to draw inferences to what extent these administrative zones correlate with the perceived and used neighbourhood environment of the children and their parents. Besides that, there were no data available on average household income on the neighbourhood level which is a further socioeconomic indicator often considered in neighbourhood studies. Moreover, we were not able to consider other individual risk factors, such as smoking during pregnancy, breastfeeding, or data on nutrition and physical activity. However, there is evidence at least for Germany that parental overweight, high birth weight and socioeconomic indicators are the main determinants for overweight in early childhood [16], and we were able to consider all these individual determinants in our multilevel model. Finally, for analysing random-slopes and cross-level interactions 18 level 2 units might be too low. Although simulation studies showed that 18 level 2 units may be enough for hierarchical logistic regression modelling [54] our random intercept estimates should be interpreted with caution because they showed wide confidence intervals.

One of the major strengths of our study is that we could provide new evidence for the population group of 
younger children because there is still a lack of knowledge how contextual neighbourhood factors influence health in early childhood, especially in Germany. To the best of our knowledge it is one of the first studies for this age group in Germany analysing neighbourhood SEP simultaneously with a wide range of individual socioeconomic indicators and the additional consideration of maternal BMI and birth weight as further important individual risk factors. Our BMI measures for children were derived from objectively measured body weight and height by trained staff, thus no bias occurred because of self-reported measures by the parents.

\section{Conclusions}

Our study showed that the socioeconomic context in which young children live was associated with overweight independently from individual overweight determinants. Although individual determinants play a more important role in explaining differences in overweight between neighbourhoods, contextual neighbourhood factors should be additionally taken into account for the identification of vulnerable neighbourhoods and population groups. Public health interventions which consider neighbourhood context could be more effective than interventions targeting only at individual risk factors.

\section{Availability of data and materials}

The dataset supporting the results of this article may be requested from the Bavarian Health and Food Safety Authority, steering committee of the health monitoring units in Bavaria, Munich, Germany.

\section{Abbreviations \\ SEP: socioeconomic position; BMI: body mass index; OR: odds ratio; $\mathrm{Cl}$ : confidence interval; GME: Gesundheits-Monitoring-Einheiten; IOTF: International Obesity Task Force; PedNSS: Pediatric Nutrition Surveillance System; CDC: Centres for Disease Control and Prevention; PCA: principal component analysis; VIF: variance inflation factor; PCV: proportional change in variance.}

\section{Competing interests}

The authors declare that they have no competing interests.

\section{Authors' contribution}

SAS performed the statistical analysis and wrote the initial draft of the manuscript. HF and GB participated in the conceptualization of the study, in its design and coordination. RvK, HF and GB helped to draft the manuscript. All authors read and approved the final manuscript.

\section{Authors' information \\ SAS receives a doctoral scholarship within the framework of the Jufo-Salus (Junior Research Group "The City as a healthy living environment independent of social inequalities") which is funded by the foundation 'Fritz und Hildegard Berg- Stiftung' within the 'Stifterverband für die Deutsche Wissenschaft e.V.', Essen, Germany.}

\section{Acknowledgements}

The authors thank all parents for participating in the surveys, Lana Hendrowarsito and Birgit Reineke for data management, the GME Study Group of the first three surveys 2004-07, the Department of Health and
Environment in the city of Munich (Sylvia Kranebitter, Heidi Mayrhofer, Gertraud Rohrhirsch and Brigitte Weise), the Department of Statistic in the city of Munich (Ronald Bauch), and the Jufo-Salus (Junior Research Group "The City as a healthy living environment independent of social inequalities").

\section{Author details}

'Department of Social Epidemiology, Institute for Public Health and Nursing Research, University of Bremen, Bremen, Germany. ${ }^{2}$ Institute of Social Paediatrics and Adolescent Medicine, Ludwig Maximilian University, Munich, Germany. ${ }^{3}$ Bavarian Health and Food Safety Authority, Munich, Germany.

Received: 16 May 2015 Accepted: 4 May 2016

Published online: 06 May 2016

\section{References}

1. Ng M, Fleming T, Robinson M, Thomson B, Graetz N, Margono C, et al. Global, regional, and national prevalence of overweight and obesity in children and adults during 1980-2013: a systematic analysis for the Global Burden of Disease Study 2013. Lancet. 2014;384(9945):766-81. doi:10.1016/ S0140-6736(14)60460-8.

2. de Onis M, Blossner M, Borghi E. Global prevalence and trends of overweight and obesity among preschool children. Am J Clin Nutr. 2010;92(5):1257-64. doi:10.3945/ajcn.2010.29786.

3. Dietz WH. Health consequences of obesity in youth: childhood predictors of adult disease. Pediatrics. 1998;101(3 Pt 2):518-25

4. Lobstein T, Baur L, Uauy R. Obesity in children and young people: a crisis in public health. Obes Rev. 2004;5 Suppl 1:4-104. doi:10.1111/j.1467-789X.2004. 00133.x.

5. Sacks G, Swinburn B, Lawrence M. Obesity Policy Action framework and analysis grids for a comprehensive policy approach to reducing obesity. Obes Rev. 2009;10(1):76-86. doi:10.1111/j.1467-789X.2008.00524.x.

6. Duncan C, Jones K, Moon G. Context, composition and heterogeneity: using multilevel models in health research. Soc Sci Med. 1998;46(1):97-117.

7. Diez Roux AV. Bringing context back into epidemiology: variables and fallacies in multilevel analysis. Am J Public Health. 1998;88(2):216-22. doi:10.2105/AJPH.88.2.216.

8. Diez Roux AV. A glossary for multilevel analysis. J Epidemiol Community Health. 2002;56(8):588-94. doi:10.1136/jech.56.8.588.

9. van Vuuren $C L$, Reijneveld SA, van der Wal MF, Verhoeff AP. Neighborhood socioeconomic deprivation characteristics in child (0-18 years) health studies: A review. Health Place. 2014;29:34-42. doi:10.1016/j.healthplace. 2014.05.010

10. Rajaratnam JK, Burke JG, O'Campo P. Maternal and child health and neighborhood context: the selection and construction of area-level variables. Health Place. 2006;12(4):547-56. doi:10.1016/j.healthplace.2005.08.008.

11. Leventhal T, Brooks-Gunn J. The neighborhoods they live in: The effects of neighborhood residence on child and adolescent outcomes. Psychol Bull. 2000;126(2):309-37. doi:10.1037/0033-2909.126.2.309.

12. Sellström E, Bremberg S. The significance of neighbourhood context to child and adolescent health and well-being: a systematic review of multilevel studies. Scand J Public Health. 2006;34(5):544-54. doi:10.1080/ 14034940600551251.

13. Krieger N, Williams DR, Moss NE. Measuring social class in US public health research: concepts, methodologies, and guidelines. Annu Rev Public Health. 1997;18:341-78. doi:10.1146/annurev.publhealth.18.1.341.

14. Krieger N. A glossary for social epidemiology. J Epidemiol Community Health. 2001;55(10):693-700. doi:10.1136/jech.55.10.693.

15. Galobardes B, Shaw M, Lawlor DA, Lynch JW, Davey SG. Indicators of socioeconomic position (part 1). J Epidemiol Community Health. 2006;60(1):7-12. doi:10.1136/jech.2004.023531.

16. Danielzik S, Czerwinski-Mast M, Langnase K, Dilba B, Muller MJ. Parental overweight, socioeconomic status and high birth weight are the major determinants of overweight and obesity in 5-7 y-old children: baseline data of the Kiel Obesity Prevention Study (KOPS). Int J Obes Relat Metab Disord. 2004;28(11):1494-502. doi:10.1038/sj.ijo.0802756.

17. Schellong K, Schulz S, Harder T, Plagemann A. Birth weight and long-term overweight risk: systematic review and a meta-analysis including 643,902 persons from 66 studies and 26 countries globally. PLoS One. 2012;7(10), e47776. doi:10.1371/journal.pone.0047776.

18. Bolte G, Heissenhuber A, von Kries R, Liebl B, Zapf A, Wildner M, et al. Health monitoring units in Bavaria. Concept, aims and thematic focus of the 
first survey on children's environment and health. Bundesgesundheitsblatt Gesundheitsforschung Gesundheitsschutz. 2007;50(4):476-83. doi:10.1007/ s00103-007-0191-0.

19. Cole TJ, Bellizzi MC, Flegal KM, Dietz WH. Establishing a standard definition for child overweight and obesity worldwide: international survey. BMJ. 2000:320(7244):1240-3. doi:10.1136/bmj.320.7244.1240.

20. Gallie D, Paugam S. Social precarity and social integration. Luxembourg: Office for Official Publications of the European Communities; 2003.

21. Bayerisches Staatsministerium für Arbeit und Sozialordnung Familie und Frauen. Zweiter Bericht der Staatsregierung zur sozialen Lage in Bayern. München: 2009. http://www.stmas.bayern.de/imperia/md/content/stmas/ stmas_internet/sozialpolitik/sozbericht2.pdf. Accessed 6 May 2016.

22. Scharte M, Bolte G. for the GME Study Group. Increased health risks of children with single mothers: the impact of socio-economic and environmental factors. Eur J Public Health. 2013;23(3):469-75. doi:10.1093/ eurpub/cks062.

23. Schenk L, Bau AM, Borde T, Butler J, Lampert T, Neuhauser $H$, et al. A basic set of indicators for mapping migrant status. Recommendations for epidemiological practice. Bundesgesundheitsblatt Gesundheitsforschung Gesundheitsschutz. 2006;49(9):853-60. doi:10.1007/s00103-006-0018-4.

24. Pediatric Nutrition Surveillance System (PedNSS) - PedNSS Health Indicators. Centers for Disease Control and Prevention. http://www.cdc.gov/pednss/ what_is/pednss_health_indicators.htm. Accessed 6 May 2016.

25. Hosmer DW, Lemeshow S, Sturdivant RX. Applied logistic regression. 3rd ed. Hoboken: Wiley; 2013.

26. Tabachnick BG, Fidell LS. Using multivariate statistics. 6th ed. Boston: Pearson Education; 2013.

27. Alin A. Multicollinearity. WIREs Comput Statistics. 2010;2:370-4. doi:10.1002/wics.84.

28. Harrell FE. Regression modeling strategies: with applications to linear models, logistic regression, and survival analysis. Springer series in statistics. New York: Springer; 2001.

29. Menard SW. Applied logistic regression analysis. In: Sage university papers Quantitative applications in the social sciences, vol no 07-106. 2nd ed. Thousand Oaks, Calif: Sage Publications; 2002.

30. Wang J, Xie H, Fischer JH. Multilevel models: applications using SAS. Berlin, Boston: De Gruyter; Higher Education Press; 2012.

31. Merlo J, Ohlsson H, Lynch KF, Chaix B, Subramanian SV. Individual and collective bodies: using measures of variance and association in contextual epidemiology. J Epidemiol Community Health. 2009;63(12):1043-8. doi:10. 1136/jech.2009.088310

32. Merlo J, Yang M, Chaix B, Lynch J, Rastam L. A brief conceptual tutorial on multilevel analysis in social epidemiology: investigating contextual phenomena in different groups of people. J Epidemiol Community Health. 2005:59(9):729-36. doi:10.1136/jech.2004.023929.

33. Van Buuren S. Multiple Imputation of Multilevel Data. In: Hox JJ, Roberts JK, editors. Handbook of Advanced Multilevel Analysis. New York: Routledge; 2011.

34. Allison PD. Imputation of Categorical Variables with PROC M. Philadelphia, Pennsylvania: SUGI 30 Proceedings; 2005.

35. Berglund PA. An introduction to multiple imputation of complex sample data using SAS ${ }^{\oplus}$ v9.2 (Paper 265-2010). Seattle, Washington: Proceedings of the SAS Global Forum; 2010.

36. Ault K. Multiple Imputation for Ordinal Variables: A Comparison of SUDAAN PROC IMPUTE and SAS ${ }^{\oplus}$ PROC MI. Seattle, Washington: 20th Annual SouthEast SAS Users Group (SESUG) Conference; 2012.

37. Oliver LN, Hayes MV. Effects of neighbourhood income on reported body mass index: an eight year longitudinal study of Canadian children. BMC Public Health. 2008:8:16. doi:10.1186/1471-2458-8-16.

38. Oliver LN, Hayes MV. Neighbourhood socio-economic status and the prevalence of overweight Canadian children and youth. Can J Public Health. 2005;96(6):415-20.

39. Grow HM, Cook AJ, Arterburn DE, Saelens BE, Drewnowski A, Lozano P. Child obesity associated with social disadvantage of children's neighborhoods. Soc Sci Med. 2010;71(3):584-91. doi:10.1016/j.socscimed.2010.04.018.

40. Koller D, Mielck A. Regional and social differences concerning overweight, participation in health check-ups and vaccination. Analysis of data from a whole birth cohort of 6-year old children in a prosperous German city. BMC Public Health. 2009:9:43, doi:10.1186/1471-2458-9-43.

41. Lange D, Wahrendorf M, Siegrist J, Plachta-Danielzik S, Landsberg B, Müller MJ. Associations between neighbourhood characteristics, body mass index and health-related behaviours of adolescents in the Kiel Obesity Prevention
Study: a multilevel analysis. Eur J Clin Nutr. 2011;65(6):711-9. doi:10.1038/ Ejcn.2011.21.

42. Veugelers PJ, Fitzgerald AL. Prevalence of and risk factors for childhood overweight and obesity. CMAJ. 2005;173(6):607-13. doi:10.1503/cmaj.050445.

43. Janssen I, Boyce WF, Simpson K, Pickett W. Influence of individual- and arealevel measures of socioeconomic status on obesity, unhealthy eating, and physical inactivity in Canadian adolescents. Am J Clin Nutr. 2006;83(1):139-45.

44. Diez Roux AV, Mair C. Neighborhoods and health. Biology of Disadvantage: Socioeconomic Status and Health. 2010;1186:125-45. doi:10.1111/j.17496632.2009.05333.x

45. Schreier HM, Chen E. Socioeconomic status and the health of youth: multilevel, multidomain approach to conceptualizing pathways. Psychol Bull. 2013;139(3):606-54. doi:10.1037/a0029416.

46. Chaix B. Geographic life environments and coronary heart disease: a literature review, theoretical contributions, methodological updates, and a research agenda. Annu Rev Public Health. 2009;30:81-105. doi:10.1146/ annurev.publhealth.031308.100158.

47. Daniel M, Moore S, Kestens Y. Framing the biosocial pathways underlying associations between place and cardiometabolic disease. Health Place. 2008 14(2):117-32. doi:10.1016/j.healthplace.2007.05.003.

48. Robert SA. Socioeconomic position and health: the independent contribution of community socioeconomic context. Annu Rev Sociol. 1999:25:489-516.

49. Schulz AJ, Kannan S, Dvonch JT, Israel BA, Allen A, James SA, et al. Social and physical environments and disparities in risk for cardiovascular disease: the healthy environments partnership conceptual model. Environ Health Perspect. 2005;113(12):1817-25. doi:10.1289/ehp.7913.

50. Black JL, Macinko J. Neighborhoods and obesity. Nutr Rev. 2008;66(1):2-20. doi:10.1111/j.1753-4887.2007.00001.x.

51. Bolte G, Pauli A, Hornberg C. Environmental Justice: Social Disparities in Environmental Exposures and Health: Overview. In: Jerome ON, editor. Encyclopedia of Environmental Health. Burlington: Elsevier; 2011. p. 459-70.

52. Bolte G, Tamburlini G, Kohlhuber M. Environmental inequalities among children in Europe-evaluation of scientific evidence and policy implications. Eur J Public Health. 2010;20(1):14-20. doi:10.1093/eurpub/ckp213.

53. Brulle RJ, Pellow DN. Environmental justice: human health and environmental inequalities. Annu Rev Public Health. 2006;27:103-24. doi:10.1146/annurev.publhealth.27.021405.102124.

54. Austin PC. Estimating Multilevel Logistic Regression Models When the Number of Clusters is Low: A Comparison of Different Statistical Software Procedures. Int J Biostatistics. 2010;6(1). doi:10.2202/1557-4679.1195

\section{Submit your next manuscript to BioMed Central and we will help you at every step:}

- We accept pre-submission inquiries

- Our selector tool helps you to find the most relevant journal

- We provide round the clock customer support

- Convenient online submission

- Thorough peer review

- Inclusion in PubMed and all major indexing services

- Maximum visibility for your research

Submit your manuscript at www.biomedcentral.com/submit
) Biomed Central 